\title{
Demanda de irrigação da cultura da banana na bacia do Rio São Francisco
}

\author{
Wallisson da S. Freitas ${ }^{1}$, Márcio M. Ramos ${ }^{1} \&$ Sidnei L. da Costa ${ }^{2}$
}

\begin{abstract}
RESUMO
Visando subsidiar o planejamento de projetos agrícolas para o dimensionamento e gestão de recursos hídricos, estimouse e se espacializou a demanda de irrigação da cultura da banana (Musa spp.), na bacia do Rio São Francisco. Utilizaram-se séries históricas de dados de 81 estações climáticas distribuídas na bacia e se calcularam, para cada estação, os valores máximos diários e o total anual da evapotranspiração de referência (ETo), da evapotranspiração da cultura (ETc), da demanda suplementar da cultura e da demanda suplementar de irrigação (este com eficiência de $77,2 \%$ ). Com base nos resultados obtidos, concluiu-se que: (a) a ETc máxima diária variou em 51\% da bacia, de 6,6 a 7,6 mm apresentando média anual de $1.884 \mathrm{~mm}$; (b) em média, a demanda suplementar da cultura foi $1.735 \mathrm{~mm}$ por ano, $149 \mathrm{~mm}$ inferior à ETc; (c) o fato do sistema funcionar com 77,2\% de eficiência, ao invés de 90\%, implica em acréscimo estimado de 36.688.050 $\mathrm{m}^{3}$ de água por ano somente para a mesorregião no Norte de Minas.
\end{abstract}

Palavras-chave: consumo hídrico, projetos agrícolas, SIG

\section{Irrigation demand of banana crop in San Francisco River basin}

\begin{abstract}
The irrigation water demand of banana crop (Musa spp.) was estimated and spatialized in the San Francisco River basin, in order to help agricultural project planning and water resource management. Historical data series relative to 81 climatic stations distributed throughout the basin were used. The maximum daily values and the annual total values of the reference evapotranspiration (ETo), crop evapotranspiration (ETc), supplementary demand of the crop and the supplementary irrigation demand ( $77.2 \%$ efficiency) were calculated for each station. According to the results, the in $51 \%$ of the basin, maximum daily ETc varied from 6.6 to $7.6 \mathrm{~mm} \mathrm{~d}^{-1}$, with an annual average of $1,884 \mathrm{~mm}$; the supplementary annual demand of the crop was $1,735 \mathrm{~mm}$, corresponding to $149 \mathrm{~mm}$ less than $\mathrm{ET}$; and the fact that irrigation system operates at $77.2 \%$ efficiency instead of $90 \%$ implies an increment of $36,688,050 \mathrm{~m}^{3}$ of water per year only in the mesoregion north of Minas Gerais.
\end{abstract}

Key words: water requirements, agricultural project, GIS

1 DEA/UFV. Av. PH Rolfs, s/n, CEP 36570-000, Viçosa, MG. Fone: (31) 8768-1993. E-mail: wallfreitas@yahoo.com.br; 3899-1914. E-mail: mmramos@ufv.br

2 Engenheiro Agrônomo, Ms. Economia Aplicada, Superintendente da Heringer, CEP 36900-000, Manhuaçu, MG. Fone: (33) 9106-1973. E-mail: slcosta@uol.com.br 


\section{INTRODUÇÃO}

A banana é a fruta mais consumida in natura no mundo, cujo cultivo se concentra nos países de clima tropical. Em 2001 a produção mundial foi de aproximadamente 68,6 milhões de tonelada (FAO, 2002). Segundo dados do IBGE (2004), no Brasil a área cultivada em 2004 foi de 491.042 ha com uma produção de 6,583 milhões de toneladas, sendo os maiores produtores: São Paulo, Bahia, Santa Catarina, Minas Gerais, Pará e Pernambuco.

Nos estados banhados pelo Rio São Francisco se destacam pólos produtores localizados principalmente nos Estados de Minas Gerais, Bahia e Pernambuco. Em Minas Gerais se sobressai a mesorregião do Norte de Minas (que inclui, entre outras, as microrregiões de Janaúba, Montes Claros e Januária), com área colhida de 11.970 ha e, na Bahia, as microrregiões de Bom Jesus da Lapa, Jacobina e Juazeiro, com áreas colhidas de 2.662, 2.634 e 2.585 ha, respectivamente, enquanto em Pernambuco é salientada a microrregião de Petrolina, com área colhida de 5.417 ha (IBGE, 2004).

Por se tratar de cultura de clima tropical, a bananeira exige temperatura elevada, boa disponibilidade de água no solo para seu pleno desenvolvimento (Alves et al., 1999) e condições predominantes na bacia do São Francisco, masdevido à má distribuição de chuvas na bacia, seu cultivo se torna mais viável através da irrigação.

Embora seja uma técnica que vise ao aumento da produtividade das culturas, em especial em regiões áridas e semiáridas, a irrigação apresenta grande impacto nas disponibilidades hídricas, uma vez que grandes demandas de água são alocadas principalmente para as regiões onde se verificam altas concentrações de áreas irrigadas. Especial atenção deve ser dada a essas regiões quanto ao gerenciamento da água, uma vez que, segundo Carvalho (1998), a maioria dos projetos envolvendo recursos hídricos não tem alcançado os níveis desejados de produtividade em virtude, basicamente, das dificuldades operacionais encontradas no campo, não levadas em consideração durante o planejamento.

Muitas vezes, o dimensionamento hidráulico de projetos de irrigação tem como referência valores de evapotranspiração médios mensais, que podem variar temporalmente até $50 \%$ e, portanto, não representar valores extremos de períodos menores, em especial os diários (Dantas Neto, 2002).

O conhecimento da necessidade hídrica máxima diária e total anual de determinada cultura em uma região possibilita dimensionar a rede hidráulica de projetos de irrigação (canais, tubulações, reservatórios e estações de bombeamento) e estimar o volume total de água retirado para suprir suas necessidades hídricas, informação esta fundamental no gerenciamento de recursos hídricos e no planejamento de projetos hidroagrícolas.

A determinação da necessidade hídrica é baseada na evapotranspiração da cultura (ETc), definida em geral, a partir do produto entre o coeficiente de cultura $(\mathrm{Kc})$ e a evapotranspiração de referência (ETo).

O coeficiente de cultura (Kc) varia de acordo com as fases fenológicas e seus valores para a banana são $0,4,0,7,1,0$, 0,9 e 0,75 nas fases inicial, de desenvolvimento, intermedi- ária, final do ciclo e colheita, respectivamente (Doorenbos \& Kassan, 1994); no entanto, segundo Cordeiro (2003), no caso de regiões semi-áridas a demanda de água pela bananeira em seu primeiro ciclo se inicia com $45 \%$ da evapotranspiração de referência (ETo) nos primeiros 70 dias, elevando-se para 85\% da ETo aos 210 dias (fase de formação dos frutos) atingindo o máximo de $110 \%$ da ETo aos 300 dias.

Conforme Moreira (1987), apud Simão (2002), a quantidade de água necessária à bananeira varia de 3 a 8 mm d ${ }^{-1}$; já Marinato (1980) cita que o consumo anual de água pela bananeira pode variar de 1.200 a $1.800 \mathrm{~mm}$, enquanto para Robinson \& Alberts (1989) esses valores podem variar de 1.200 a $2.690 \mathrm{~mm}$, dependendo das condições climáticas locais.

Teixeira et al. (2002), em trabalhos conduzidos na microrregião de Petrolina, PE, verificaram que a evapotranspiração da cultura da banana, cv. Pacovan, determinada pelo método da razão de Bowen, foi $1.210 \mathrm{~mm}$ entre os 120 dias após o plantio (maio, 1999) e a primeira colheita (abril, 2000), com valor médio de $3,8 \pm 1,1 \mathrm{~mm} \mathrm{~d}^{-1}$; para o segundo ciclo (término da colheita em novembro de 2000), o consumo foi de $880 \mathrm{~mm}$, com média de 4,0 $\pm 1,2 \mathrm{~mm} \mathrm{~d}^{-1}$; de acordo com os mesmos autores, nas condições edafoclimáticas do Pólo Petrolina/Juazeiro os valores de Kc variaram entre 0,6 e 1,1 e entre 1,1 e 1,3, respectivamente, nos primeiro e segundo ciclos.

Nas condições climáticas do Norte de Minas, Coelho et al. (2003) desenvolveram, no ano de 2001, uma equação polinomial de ordem 3 que relaciona o Kc com os dias após o plantio (dap) da bananeira. Segundo tal equação, os valores de Kc que resultaram em máximas produtividades em experimentos de campo, foram de 0,55, 0,80, 1,10, 1,40 e 1,05 , respectivamente, aos $60,150,220,300$ e 400 dap mas, para efeitos práticos, Oliveira et al. (2005) sugerem, para esta mesma região, o uso de Kc igual a 1,1 para a cultura da banana com ciclo acima de 360 dias após o plantio.

Na bacia do Rio São Francisco a cultura da banana vem difundindo nos últimos anos e há necessidade de se disponibilizar, aos técnicos e planejadores, informações acerca de suas necessidades hídricas. Desta forma se objetivou, neste trabalho, estimar e espacializar, em forma de mapas, a evapotranspiração da cultura, a demanda suplementar da cultura e a demanda suplementar de irrigação para a cultura da bananeira na bacia do São Francisco.

\section{MATERIAL E MÉTODOS}

Séries históricas de dados diários do clima de 81 localidades na bacia do Rio São Francisco foram utilizadas, sendo 28 em Minas Gerais, 38 na Bahia, uma em Sergipe, seis em Alagoas e oito em Pernambuco. Estimaram-se, em cada localidade, os valores diários da evapotranspiração de referência (ETo), da precipitação efetiva, da evapotranspiração da cultura (ETc), da demanda suplementar da cultura e da demanda suplementar de irrigação.

A metodologia para determinação da evapotranspiração de referência (ETo), atualmente aceita pelos pesquisadores e 
utilizada no presente trabalho, é a evapotranspiração de uma cultura hipotética, com altura de $0,12 \mathrm{~m}$, resistência aerodinâmica da superfície de $70 \mathrm{sm}^{-1}$ e albedo de 0,23, denominada Método de FAO-Penman-Monteith (Sediyama, 1996). A precipitação efetiva foi determinada com $25 \%$ de probabilidade, ou seja, em um, a cada quatro anos, existe a probabilidade do valor da precipitação efetiva ser inferior à de projeto não atendendo, no todo, à demanda da cultura.

A ETo e a precipitação efetiva foram obtidas, em cada dia do ano, através do software IRRIGA (SISDA 3.5), desenvolvido no âmbito da Universidade Federal de Viçosa (UFV) voltado, dentre outras, para o manejo do sistema de irrigação e da água. Neste software se utilizaram dados das Normais Climatológicas dos anos de 1961 a 1990.

A evapotranspiração da cultura (ETc) foi calculada, para cada dia do ano, conforme metodologia de Keller \& Bliesner (1990), utilizando-se a Eq. 1, com valores de Ks igual a 1, por se tratar de irrigação localizada, e Kl também igual a 1 , por ser a área sombreada em $100 \%$. Adotou-se Kc igual a 1,15 (Doorenbos \& Kassam, 1994; Oliveira et al., 2005; Oliveira, 1999; Rodrigues et al., 2002), recomendado para condições de pleno estabelecimento da cultura.

$$
\mathrm{ETc}_{\mathrm{i}}=\mathrm{ETo}_{\mathrm{i}} \mathrm{Kc}_{\mathrm{i}} \mathrm{Ks}_{\mathrm{i}} \mathrm{Kl}
$$

em que:

$\mathrm{ETC}_{\mathrm{i}}$ - evapotranspiração da cultura no dia i, mm

$\mathrm{ETo}_{\mathrm{i}}$ - evapotranspiração de referência no dia i, mm

$\mathrm{Kc}_{\mathrm{i}}$ - coeficiente de cultura no dia $\mathrm{i}$, adimensional

$\mathrm{Ks}_{\mathrm{i}}$ - coeficiente de umidade do solo no dia i, adimensional

$\mathrm{Kl}$ - coeficiente de localização, adimensional

A demanda suplementar da cultura, considerando-se a contribuição da chuva, foi obtida com as Eqs. 2 e 3.

$$
\begin{aligned}
& \mathrm{DSC}_{\mathrm{i}}=\mathrm{ETc}_{\mathrm{i}}-\text { PrecEfet }_{\mathrm{i}} \text {, se ETc } c_{\mathrm{i}}>\text { PrecEfet }_{\mathrm{i}} \\
& \mathrm{DSC}_{\mathrm{i}}=0, \text { se }_{\mathrm{ETc}}<\text { PrecEfet }_{\mathrm{i}}
\end{aligned}
$$

em que:

DSC $_{i}$ - demanda suplementar da cultura no dia $\mathrm{i}, \mathrm{mm}$ PrecEfet $_{i}$ - precipitação efetiva no dia i, mm

A demanda suplementar de irrigação garante que todas as plantas receberão uma lâmina maior ou igual à necessária, para suprir o déficit hídrico, calculada utilizando-se a Eq. 4 e se adotando uma eficiência de irrigação igual a 77,2\% (Ramos \& Pruski, 2003), com base nas avaliações feitas na bacia do Rio São Francisco, na cultura da banana.

$$
\mathrm{DSI}_{\mathrm{i}}=\frac{\mathrm{DSC}_{\mathrm{i}}}{\mathrm{Ea}} 100
$$

em que:

$\mathrm{DSI}_{\mathrm{i}}$ - demanda suplementar de irrigação no dia i, mm

Ea - eficiência do sistema de irrigação, \%

A partir dos 365 valores diários de cada uma das 81 localidades, obtiveram-se os valores, máximo diário e total anual, da ETo, da ETc, da demanda suplementar da cultura e da demanda suplementar de irrigação.

Os mapas temáticos da distribuição espacial dos valores máximo diário e total anual, da evapotranspiração da cultura, da demanda suplementar da cultura e da demanda suplementar de irrigação, foram obtidos com o uso do ArcView, versão 3.2a, empregando-se o interpolador IDW.

\section{RESULTADOS E DISCUSSÃO}

Os mapas temáticos da distribuição espacial dos valores da ETo máxima diária e da ETo total anual, são apresentados na Figura 1.

Verifica-se que os valores máximos diários (Figura 1A) e total anual (Figura 1B) da ETo aumentam sempre que se avança da porção sul para a norte da bacia, chegando a um valor máximo de 7,51 $\mathrm{mm} \mathrm{d}^{-1}$ em Santa Cruz, PE, e Sobradinho, BA, ambas na sub-bacia 48. Tais mapas servem como parâmetro para o gerenciamento do uso da água, possibilitando incentivar cultivos irrigados com aplicação localizada 3 com maior taxa de evapotranspiração anual, a fim de evitar perdas por evaporação direta.

Os mapas temáticos da distribuição espacial dos valores da ETc máxima diária e da ETc total anual, são apresentados na Figura 2.

O mapa de valores máximos diários (Figura 2A) da ETc pode ser usado no dimensionamento de projetos de irrigação da cultura da banana, visando atender às necessidades hídricas da cultura em épocas mais críticas do ano e operar os sistemas com maior margem de segurança, em casos de veranicos; no entanto, a não-contabilização das eventuais precipitações poderá implicar no superdimensionamento de projetos, acarretando maiores custos. A partir de seus valores espacializados, pode-se estimar, para fins de projeto, os períodos de irrigação, o turno de rega e a rede hidráulica, em determinada região cultivada com banana.

Verificou-se que os valores máximo diário (Figura 2A) e total anual (Figura 2B) da ETc aumentaram a medida em que se avançou do sul para o norte da bacia, sendo que em aproximadamente $51 \%$ da bacia se observou predomínio de valores da ETc máxima diária variando na faixa de 6,6 a $7,6 \mathrm{~mm} \mathrm{~d}^{-1}$.

Com relação à Figura 2B, tem-se que a ETc média anual para toda a bacia foi $1.884 \mathrm{~mm}$, correspondendo a $5,2 \pm 0,6 \mathrm{~mm} \mathrm{~d}^{-1}$, valor este dentro da faixa de variação citada por Simão (2002) e superior ao encontrado por Teixeira et al. (2002), em Petrolina, PE. Em 64\% da bacia prevaleceram valores entre 1.752 e $2.054 \mathrm{~mm}$ por ano, os quais foram, também, os valores predominantes encontrados nas regiões maiores produtoras de banana, como Janaúba, Bom Jesus da Lapa e o pólo Petrolina/Juazeiro.

Os mapas temáticos da distribuição espacial dos valores máximo diário e total anual da demanda suplementar da cultura estão apresentados na Figura 3.

Os valores máximos diários da demanda suplementar da cultura foram praticamente iguais aos da ETc. As pequenas reduções observadas foram mais evidenciadas na porção sul da bacia, onde o regime pluvial se concentra entre os meses 
A.

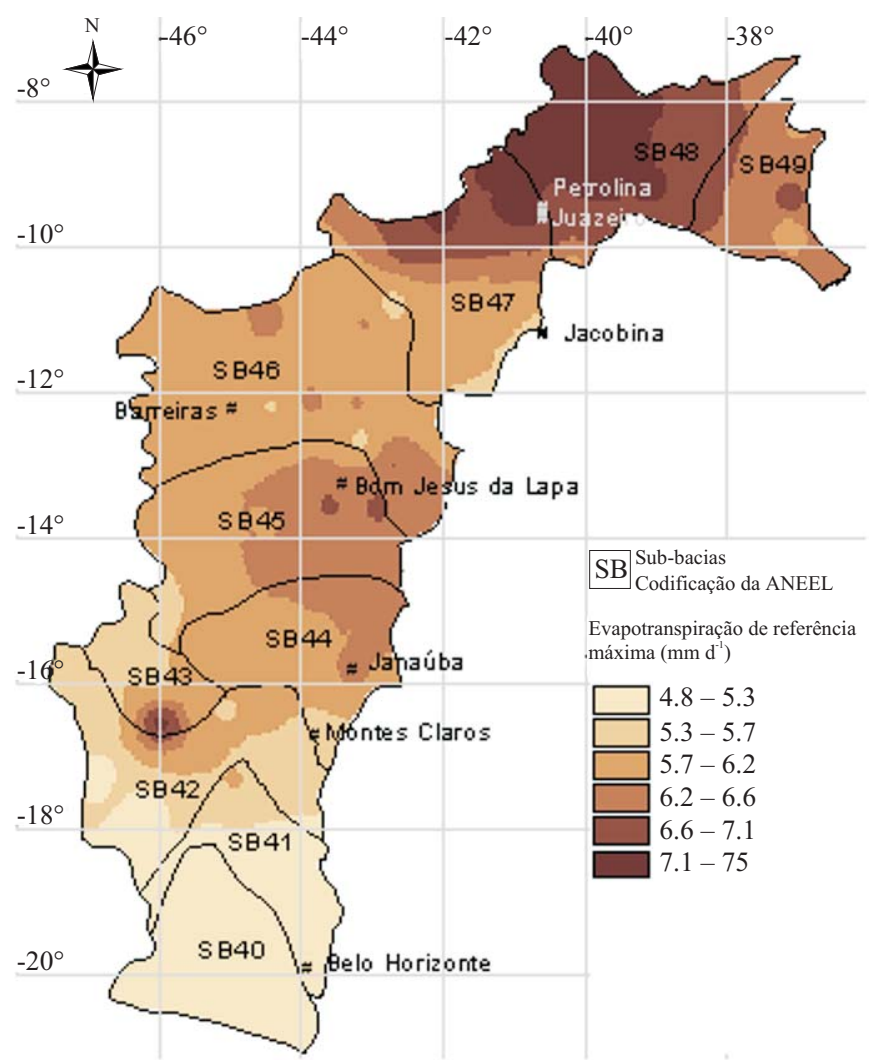

B.

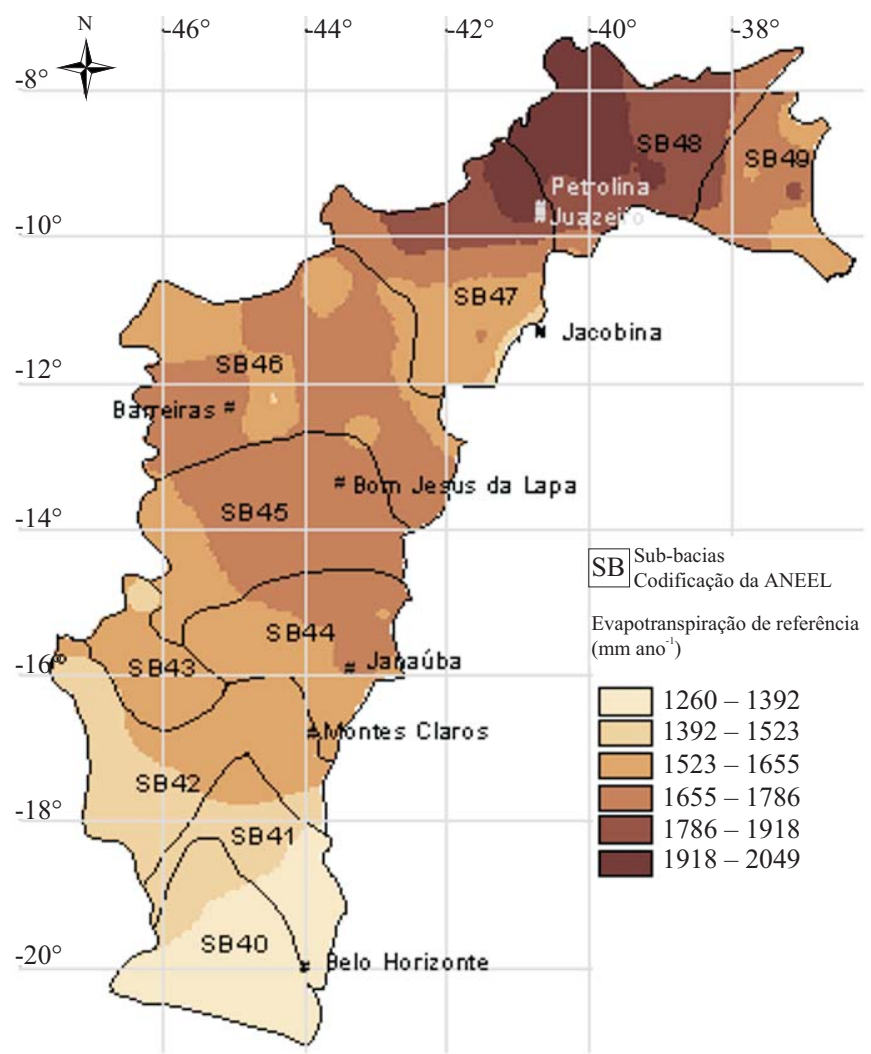

Figura 1. Valores máximo diário (A) e total anual (B) da evapotranspiração de referência na bacia do Rio São Francisco
A.

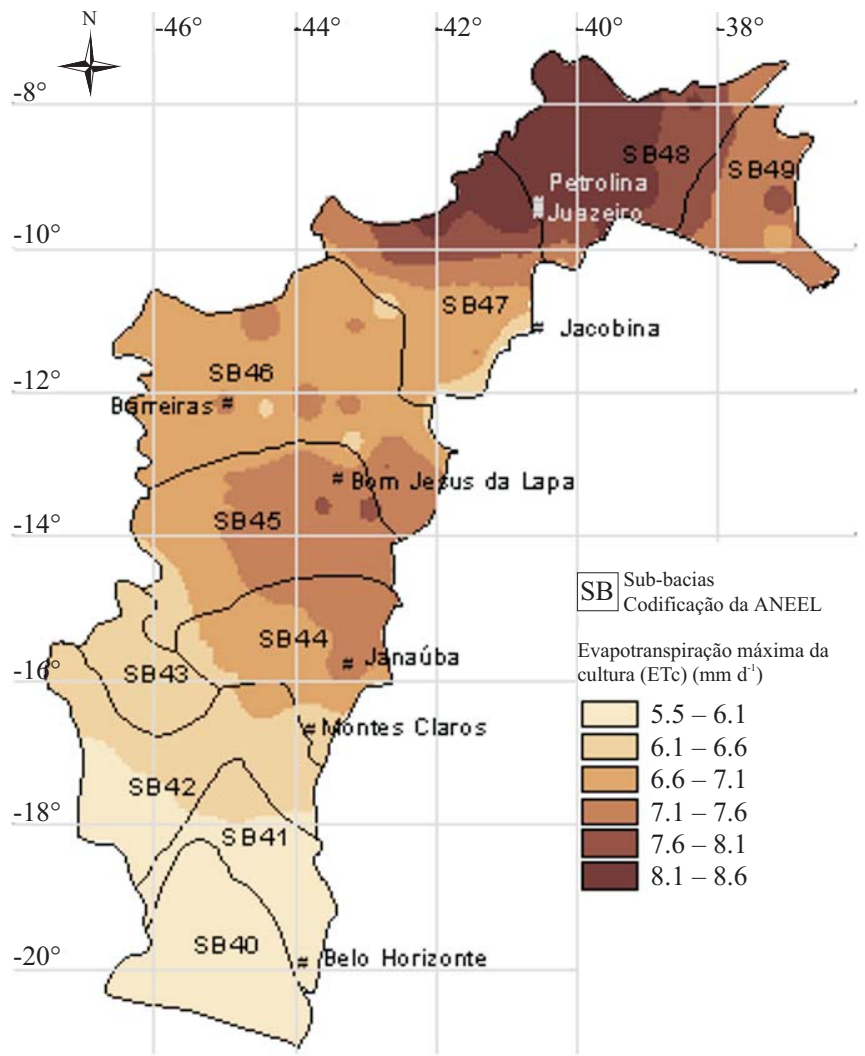

B.

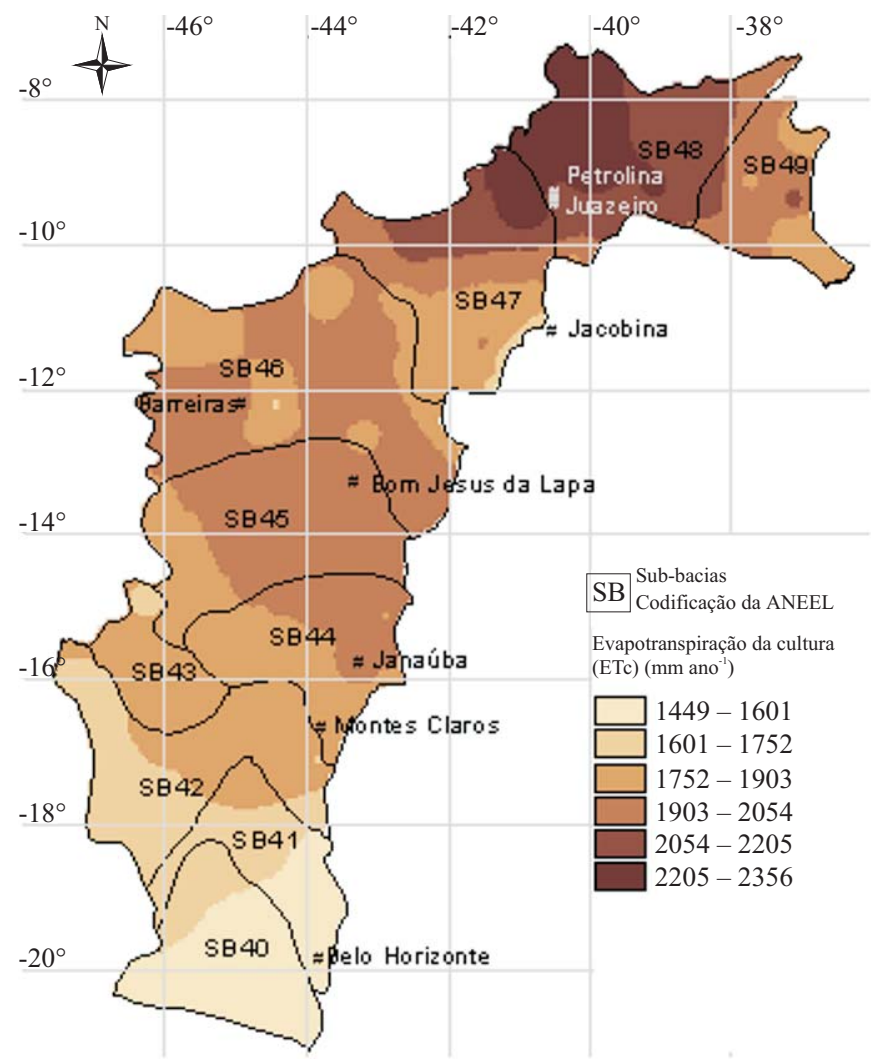

Figura 2. Valores máximo diário (A) e total anual (B) da evapotranspiração da cultura da banana na bacia do Rio São Francisco 
A.

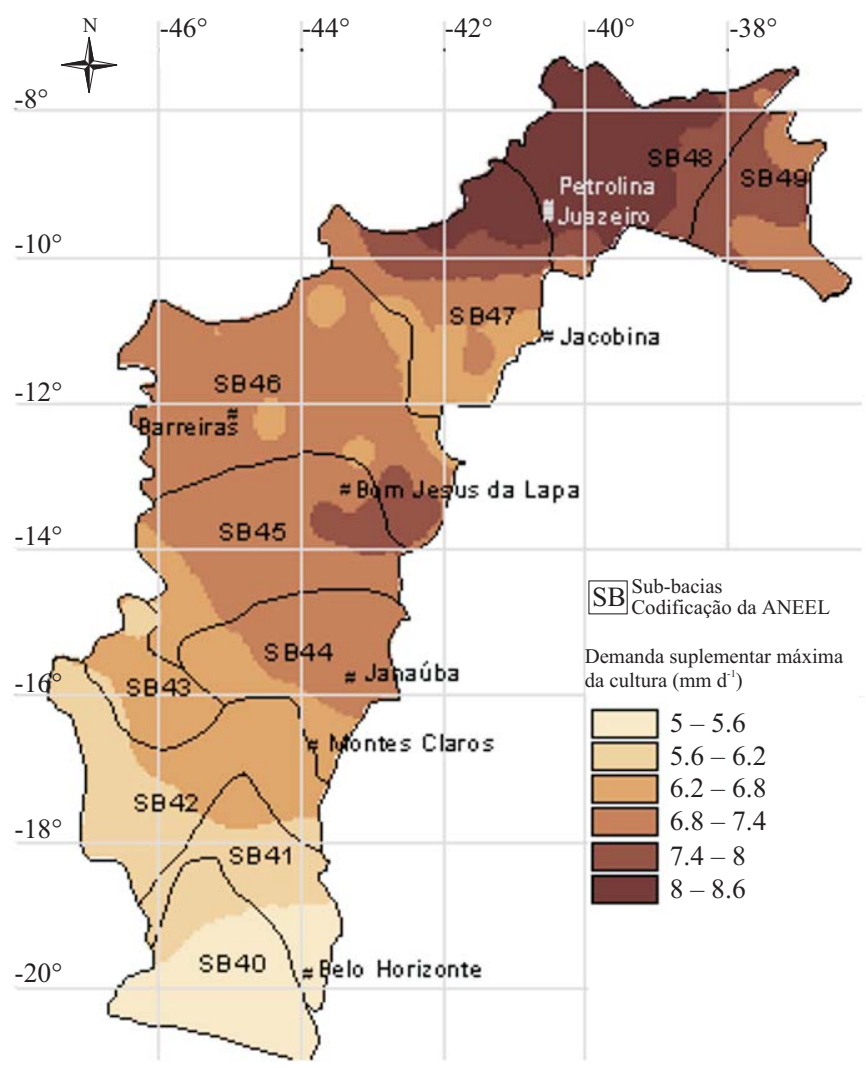

B.

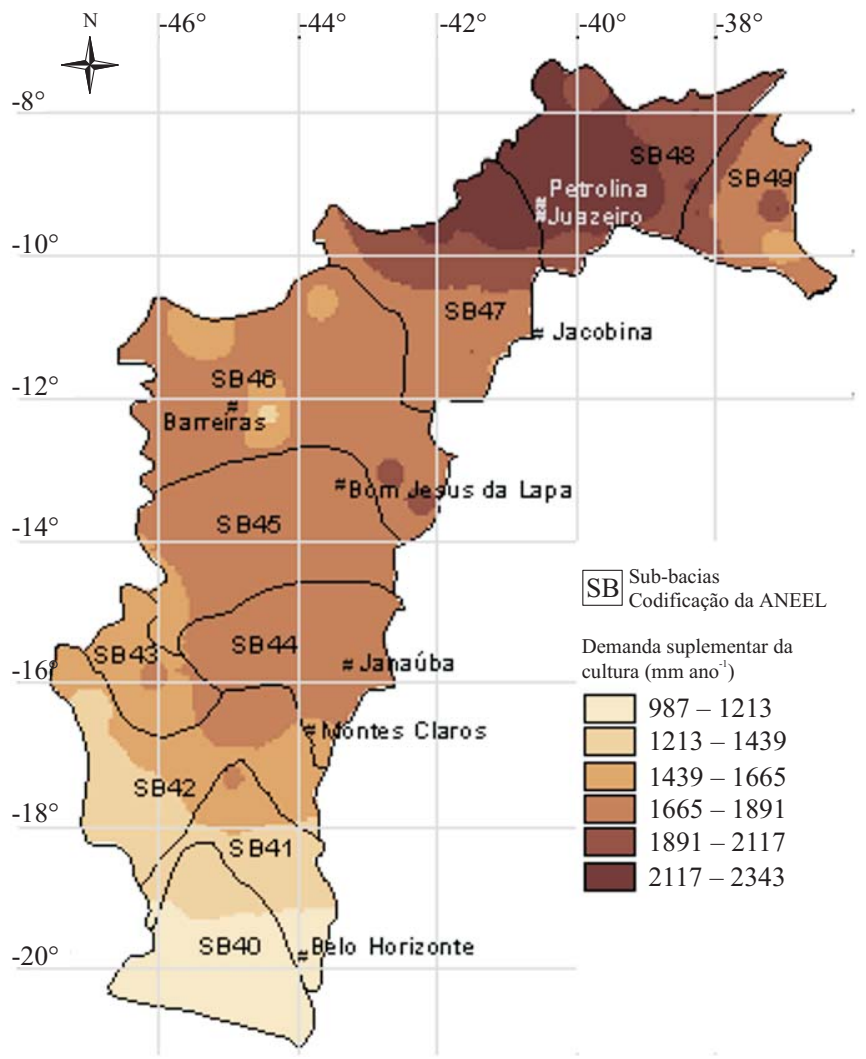

Figura 3. Valores máximo diário (A) e total anual (B) da demanda suplementar da cultura da banana na bacia do Rio São Francisco de outubro e março, período em que se observam os maiores valores da ETc. Sempre que se avança para a porção norte da bacia, a estação chuvosa tende a atrasar, resultando em menores reduções; além disso, os baixos valores totais de chuva observados na porção norte, comparados com os da porção sul, contribuem para a ocorrência de menores diferenças entre a demanda suplementar e a ETc.

Em média, a demanda suplementar da cultura na bacia foi $1.735 \mathrm{~mm}$ por ano, $149 \mathrm{~mm}$ inferior à ETc, sendo esta redução mais evidenciada na porção sul da bacia. Na cidade de Janaúba, MG, a demanda de irrigação passou de 1.924 para $1.825 \mathrm{~mm}$ por ano, em razão da contribuição da precipitação efetiva. Nas SB 42 e 44, onde se localiza a mesorregião do Norte de Minas, e na SB 45, na qual se insere a microrregião de Bom Jesus da Lapa, a demanda de irrigação anual que variava entre 1.752 a 2.054 , passou a variar entre 1.439 a $1.891 \mathrm{~mm}$ por ano, em virtude da contribuição da precipitação efetiva. Na região da divisa entre as sub-bacias 47 e 48 (região de Sobradinho, BA, e do pólo Juazeiro/Petrolina), onde se concentra grande parte da produção de banana na bacia, a redução da demanda de irrigação pela contribuição da precipitação pode ser considerada insignificante.

Os mapas temáticos da distribuição espacial dos valores máximo diário e total anual da demanda suplementar de irrigação (sistema de irrigação com eficiência de 77,8\%) são apresentados nas Figuras 4A e 4B, respectivamente.

A demanda suplementar de irrigação máxima diária (Figura 4A) teve valor médio de $9 \mathrm{~mm}$ e valor máximo de 11,2 mm em Santa Cruz, PE (SB 48).

Para efeito de comparação pode-se verificar, por exemplo, que a demanda suplementar máxima da cultura na cidade de Janaúba, MG, e no pólo Juazeiro/Petrolina, que era 7,3 e $8,2 \mathrm{~mm} \mathrm{~d}^{-1}$, passou a 9,5 e $10,6 \mathrm{~mm} \mathrm{~d}^{-1}$, respectivamente, ao se considerar a eficiência do sistema. Este aumento é significativo visto que implica em menor intervalo entre irrigações, ampliação da rede hidráulica, maior gasto de energia e maior consumo de água, que é tarifada nos perímetros irrigados.

A demanda suplementar de irrigação na bacia (Figura 4B) foi, em média, de $2.248 \mathrm{~mm}$ por ano, com valor máximo de 3.039 mm por ano em Sobradinho, BA; em Janaúba, MG, e no pólo Juazeiro/Petrolina, a demanda suplementar de irrigação foi 2.365 e 2.834 mm, respectivamente.

Para evidenciar a necessidade de aumentar a eficiência dos sistemas de irrigação na bacia, considerou-se a demanda suplementar da cultura da banana na mesorregião do Norte de Minas, igual a $1.665 \mathrm{~mm}$ por ano (média entre os intervalos predominantes na mesorregião, 1.439 e $1.891 \mathrm{~mm}$ por ano); sendo 11.970 ha a área total cultivada com banana nesta mesorregião (IBGE, 2004), haveria uma demanda anual de 199.300.199 $\mathrm{m}^{3}$ de água para suprir as deficiências hídricas da cultura da banana. Considerando-se a eficiência de 77,2\%, a demanda suplementar de irrigação seria 2.156,5 mm anuais (média dos intervalos 1.864 e 2.449 mm por ano), o que implicaria em um consumo anual de $258.133 .050 \mathrm{~m}^{3}$, ou seja, um acréscimo de $58.832 .550 \mathrm{~m}^{3}$ de água por ano em relação ao sistema funcionando com $100 \%$ de eficiência. 


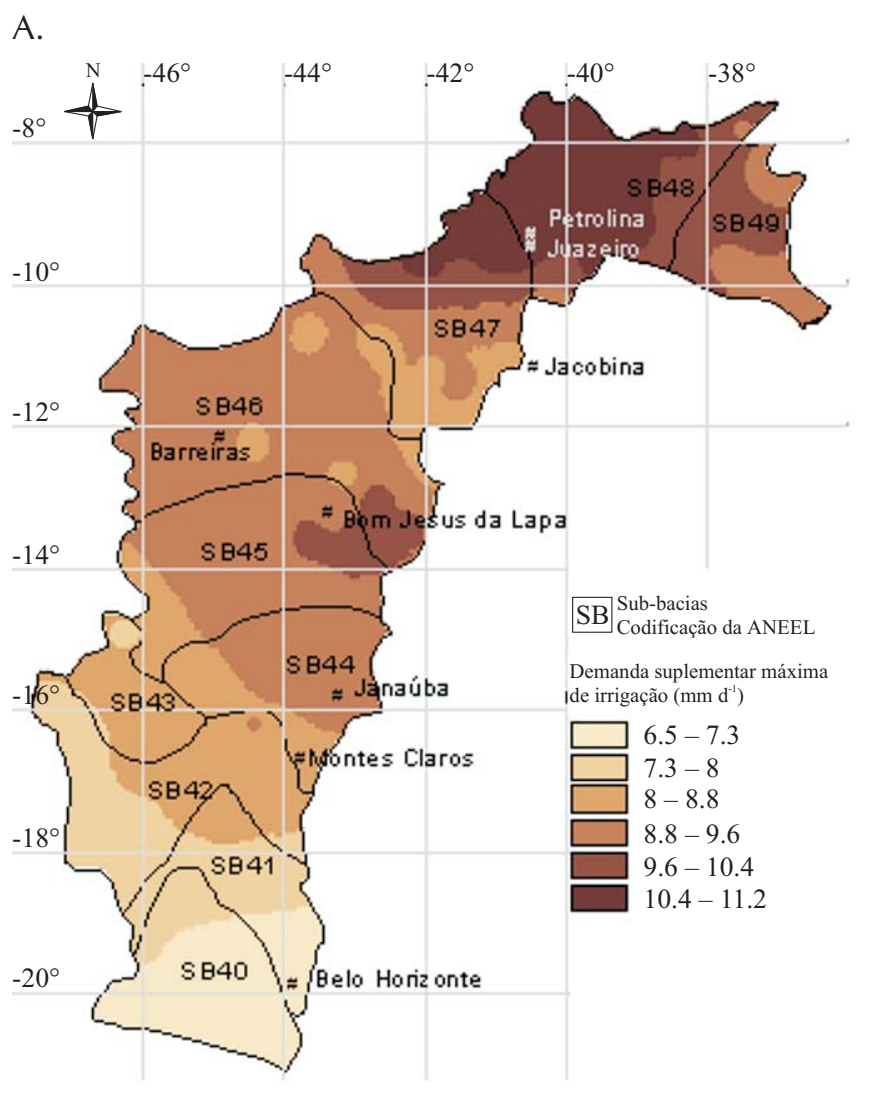

B.

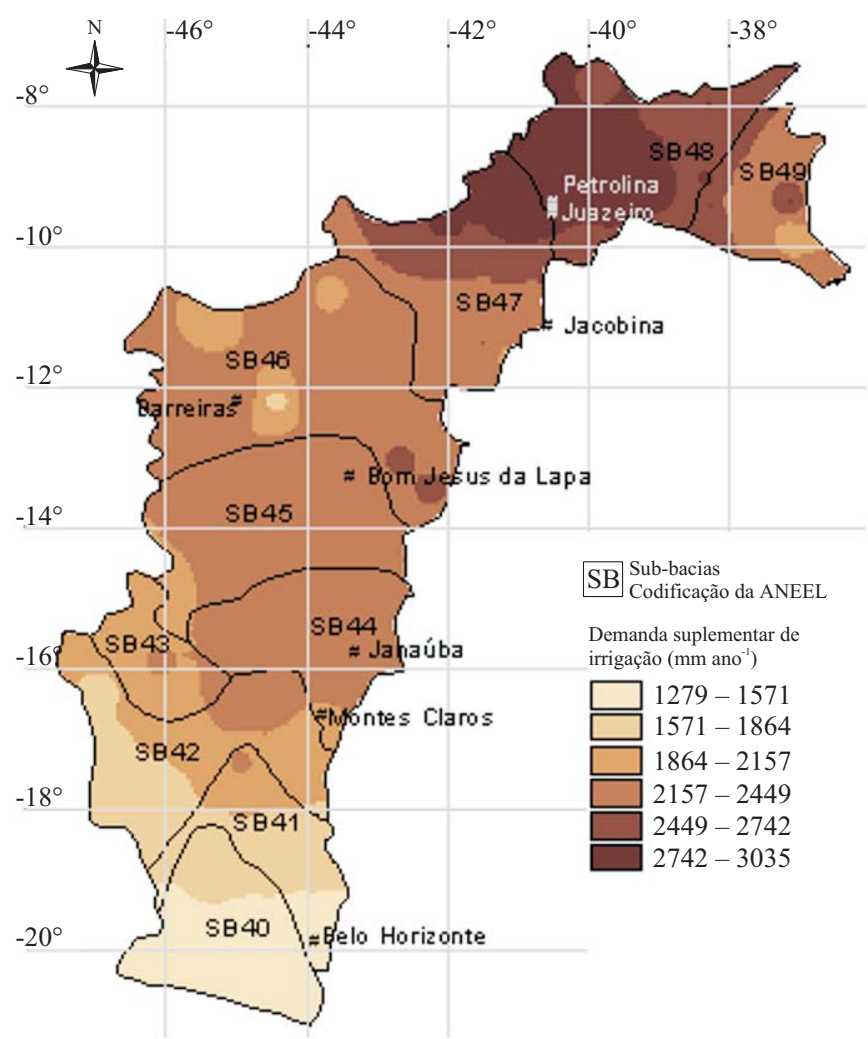

Figura 4. Valores máximo diário (A) e total anual (B) da demanda suplementar de irrigação da cultura da banana, com sistema de irrigação com eficiência de $77,2 \%$, na bacia do Rio São Francisco
Caso os sistemas e/ou os manejos fossem melhorados e passassem a operar com $90 \%$ de eficiência, valor recomendado para sistemas de irrigação por microaspersão, a demanda suplementar de irrigação para a cultura da banana na mesorregião do Norte de Minas seria aproximadamente $1.850 \mathrm{~mm}$ por ano e consumo anual de 221.445.000 $\mathrm{m}^{3}$ de água, propiciando uma economia $36.688 .050 \mathrm{~m}^{3}$, em relação ao sistema funcionando com $77,8 \%$; o que permitiria agregar-se mais 1.983 ha de bananeira sem aumentar a demanda de água para irrigação.

\section{CONCLUSÕES}

1. A evapotranspiração máxima diária da cultura da banana (ETc) variou, em 51\% da bacia, entre 6,6 e 7,6 mm, sendo o valor médio anual de $1.884 \mathrm{~mm}$.

2. A demanda suplementar da cultura foi, em média, de $1.735 \mathrm{~mm}$, enquanto a demanda suplementar de irrigação (sistema funcionando com $77,6 \%$ de eficiência) foi de $1.927 \mathrm{~mm}$.

3. Somente para as irrigações da banana na mesorregião no Norte de Minas, se fossem adotadas melhores estratégias de manejo e o sistema passasse a operar com eficiência de $90 \%$, ao invés de $77,6 \%$, haveria uma economia de água de aproximadamente $36.688 .050 \mathrm{~m}^{3}$, o que permitiria agregarse mais 1.983 ha de bananeiras sem aumentar a demanda de água para irrigação.

\section{LITERATURA CITADA}

Alves, E. J.; Oliveira, M. A.; Dantas, J. L. L.; Oliveira, S. L. Exigências climáticas. In: Alves, E.J. A cultura da bananeira: Aspectos técnicos, sócio-econômicos e agroindustriais. 2.ed. Brasília: Embrapa SPI, 1999. Cap.5, p.85-105.

Carvalho, D. F. de. Otimização do uso da água no perímetro irrigado do Gorutuba. Viçosa: UFV, 1998. 145p. Tese Doutorado

Coelho, E. F.; Costa, E. L.; Teixeira, A. H. C.; Oliveira, S. L. Irrigação da bananeira. Cruz das Almas: Embrapa Mandioca e Fruticultura, 2003. Circular Técnica, 53.

Cordeiro, Z. J. M. C. Cultivo da banana para o Projeto Formoso. Embrapa Mandioca e Fruticultura Sistema de Produção, 2003. http://sistemasdeproducao.cnptia.embrapa.br/FontesHTML/ Banana/Banana Formoso/irrigacao.htm. 25 Jun. 2004.

Dantas Neto, F. S. Recursos hídricos e suporte tecnológico a projetos hidroagrícolas: Bacia do Alto São Francisco. Viçosa: UFV; Belo Horizonte: Ruralminas; Brasília: ANA, 2002. 258p.

Doorenbos, J.; Kassam, A. H. Efeito da água no rendimento das culturas. Campina Grande: UFPB, 1994. 306p. Estudos FAO: Irrigação e Drenagem, 33.

FAO - Food and Agriculture Organization. Crop water management: Banana, 2002. http://www.fao.org/ag/aGL/aglw/cropwater/banana.stm. 29 Abr. 2007.

IBGE - Instituto Brasileiro de Geografia Estatística. PAM - Produção Agrícola Municipal, 2004.

Keller, J; Bliesner, R. D. Sprinkler and trickle irrigation. New York: Overbook, 1990. 649p. 
Marinato, R. Irrigação da bananeira. Informe Agropecuário, v.6 n.63, p.42-45, 1980.

Oliveira, S. L. Irrigação. In: Alves, E. J. A cultura da banana: Aspectos técnicos, socioeconômicos e agroindustriais, 2.ed. Brasília: Embrapa SPI; Cruz das Almas: Embrapa CNPMF, 1999. p.317-334.

Oliveira, S. L.; Borges, A. L.; Coelho, E. F.; Coelho Filho, M. A.; Silva, J. T. A. Uso da irrigação e da fertirrigação na produção integrada de banana no norte de Minas Gerais. Cruz das Almas, BA. Embrapa Mandioca e Fruticultura, 2005. 7p. Circular Técnica, 77

Ramos, M. M.; Pruski, F. F. Quantificação e análise da eficiência do uso da água pelo setor agrícola na Bacia do São Francisco. Relatório do Projeto de gerenciamento integrado das atividades desenvolvidas em terra na Bacia do São Francisco, Brasília 2003. http://www.ana.gov.br/gefsf/arquivos/ResumoExecutivo4-3.pdf. 18 Dez. 2003.
Robinson, J. C.; Alberts, A. J. Seasonal variations in the crop water-use coefficient of banana (cultivar William) in the subtropics. Scientia Horticulturae, v.40, n.3, p.215-225, 1989.

Rodrigues, M. G. V.; Souto, R. F.; Menegucci, J. L. P. Efeito da poda da última penca do cacho da bananeira prata anã (aab) irrigada na produção de frutos no Norte de Minas Gerais. Revista Brasileira de Fruticultura, v.24, n.1, p.108-110, 2002.

Sediyama, G. C. Necessidade de água para os cultivos. Brasília: ABEAS, 1996. 143p. Curso de Engenharia de IrrigaçãoMódulo 2.

Simão, A. H. Influência da percentagem de área molhada no desenvolvimento da cultura da bananeira irrigada por microaspersão. Viçosa: UFV, 2002. 80p. Dissertação Mestrado

Teixeira, A. H. C.; Bassoi, L. H.; Costa, W. P. L. B.; Silva, J. A. M.; Silva, E. E. G. Consumo hídrico da bananeira no Vale do São Francisco estimado pelo método da razão de Bowen. Revista Brasileira de Agrometeorologia, v.10, n.1, p.45-50, 2002. 